\title{
BIOÉTICA Y EJERCICIO PROFESIONAL DE LA ODONTOLOGÍA
}

\begin{abstract}
María Angélica Torres-Quintana*
Fernando Romo O.**

Resumen: La odontología enfrenta dilemas éticos importantes. Las interacciones odontólogo-paciente, el acceso a la salud dental, la conciencia de la necesidad de la población, entre otros, atraen la discusión y se deben abordar sobre la base de las éticas relevantes a la práctica profesional. Este artículo propone que la bioética, como una alternativa abierta, basada en el diálogo y comprensión de evidencias, proporcione herramientas, tanto a dentistas como a médicos, para dar solución a dilemas éticos y apoyar las discusiones interdisciplinarias e interprofesionales respecto a la mejor manera de actuar.
\end{abstract}

Palabras clave: dilemas éticos, diálogo, necesidades sociales

\section{BIOETHICS AND ODONTOLOGISTS' PROFESSIONAL PRACTICE}

\begin{abstract}
Odontology faces important ethical dilemmas: interaction patient-odontologist; access to dental health; consciousness about population's needs, among others. All of these attract discussion and have to be treated according to ethics. This paper wants to show that bioethics, as an open alternative based upon dialogue and comprehension of evidences, will provide tools to find ethical answers for dilemmas and for inter-disciplinary and inter-professional discussions.
\end{abstract}

Key words: ethical dilemmas, dialogue, social needs

\section{BIOÉTICA E O EXERCICIO PROFISSIONAL DA ODONTOLOGIA}

Resumo: A odontologia enfrenta dilemas éticos importantes, entre outros apontamos os seguintes: as relações odontólogopaciente, o acesso à saude dental, a consciencia da necessidade da população, entre outros, atraem a discussão e devem ser analisados à luz das éticas relevantes da prática profissional. Este artigo propõe que a bioética, como uma alternativa aberta, embasada no diálogo e compreensão de evidencias, proporcione ferramentas, tanto aos dentistas como aos médicos, para solucionar dilemas éticas e apoiar as discussões interdisciplinares e interprofissionais a respeito da melhor maneira de agir.

Palavras chave: dilemas éticos, diálogo, necessidades sociais

* Centro Interdisciplinario de Estudios en Bioética, Universidad de Chile

** Clínica Integral del Adulto y Departamento de Patología, Facultad de Odontología, Universidad de Chile Correspondencia: mantorre@uchile.cl 


\section{Introducción}

El análisis y la reflexión ética formal son componentes esenciales en la toma de decisiones de los profesionales de la salud. Todas las recomendaciones y procedimientos para la realización de tratamientos tienen una base ética y una consecuencia. Los odontólogos, en cada momento de su vida profesional, se ven enfrentados a conflictos de valores, donde la decisión final afectará el bienestar de sus pacientes en forma importante, por lo que se trata de una elección moral. Las conductas morales son aquellas que pueden tener buenas o malas consecuencias y pueden, por lo tanto, ser evaluadas como correctas o erróneas usando un criterio objetivo razonado. La ética es la "ciencia de la moral”, es la reflexión filosófica que permite esclarecer y fundamentar acerca de lo bueno y lo malo. Ocasionalmente se produce una confusión entre la noción de ética y ley; ésta se distingue de la ética, y consecuentemente de la moral, en cuanto institución social de reglas de acción obligatorias dictadas por una autoridad formalmente reconocida y con poder de fuerza. La ley debe ser entendida como un consenso público, frecuentemente temporal, es decir, como una aproximación a la moral(1).

El ejercicio de la odontología es considerado "una profesión", es decir, un trabajo aprendido, mediante el cual el individuo trata de solucionar sus necesidades materiales y de las personas a su cargo, servir a la sociedad y perfeccionarse como ser moral(2). Toda profesión se hace y ejerce en sociedad, es por y para los demás, por eso su carga moral. Cuando una profesión ya no es útil a la sociedad que le dio origen ésta la dejará desaparecer.

La aparición de los oficios o profesiones viene de la mano con ciertos secretos o formas únicas de hacer las cosas y, con ellos, los códigos (juramentos para mantener el prestigio de la familia o grupo) que se transmiten de gene- ración en generación. Estos códigos, tipo promesa-juramento, se fueron extendiendo a los grupos profesionales donde tomaron la forma de normas morales que regulaban las relaciones de los sujetos dentro del grupo: "una ética profesional" "deontología" o teoría de los deberes (deber ser)(3). En la actualidad, son muchas las profesiones que se han dado un código moral representativo de las normas y valores que sustentan al grupo. Constituye un valioso instrumento de regulación de la conducta de los especialistas y de sus relaciones con los consumidores de sus productos o servicios; en suma, son un medio de educación moral.

La profesión implica también espíritu de servicio. El profesional tiene una responsabilidad mayor, debido al caudal de conocimiento y capacitación que ha adquirido. Todo profesional se convierte así en un servidor de los demás, pues ha adquirido el derecho de ejercer su profesión y el deber de hacerlo siempre bien $(4,5)$. Es aquí donde entra en juego "la vocación", lo más singular que puede tener un ser humano; es el llamado de lo más interno e íntimo y está cargado de aspectos y elementos éti$\cos$. Por desgracia, la profesión no siempre coincide con la vocación, lo que puede provocar un desequilibrio psicológico y una fuente de malestar en el sujeto, además de un perjuicio para la empresa. Cuando la profesión coincide con la vocación ningún trabajo se hace pesado; hay entrega y dedicación.

Los cirujano dentistas (profesionales odontólogos) son para la sociedad expertos en conocimientos elevados y habilidades especificas, comprometidos individual y colectivamente a dar prioridad al bienestar de sus pacientes. Consecuentemente, cuando alguien se recibe de odontólogo toma un compromiso con la comunidad y acepta las normas y obligaciones de su profesión. Éstas constituyen la esencia de la "ética dental". Prácticamente desde 
sus inicios la práctica dental ha estado basada en la búsqueda del bien del paciente (ética tradicional, aristotélica, basada en las virtudes)(6). Sin embargo, debido al gran desarrollo científico y tecnológico de la medicina, a la institucionalización y especialización de los cuidados en salud, al incremento de una sociedad pluralista, al aumento de la presión sobre los recursos limitados y al rol creciente del uso de la ley para resolver los conflictos, se ha replanteado la ética dental en el mundo entero. El completo orden de las valoraciones éticas en odontología y los diferentes planteamientos para su posible resolución no han sido aún bien definidos(7).

El odontólogo raramente se ve enfrentado a decisiones de vida o muerte, pero debe asumir y dar solución a complejas cuestiones éticas. El propósito de este artículo es presentar una breve historia de la ética profesional en odontología y analizar someramente los cuestionamientos "éticos odontológicos" desde una visión bioética, es decir, a la luz de los valores y principios morales. Se trata de observar la conducta humana en el ámbito de las ciencias de la vida y de la salud, intentado entregar pautas que faciliten el análisis ético y la toma de decisiones clínicas.

\section{Ética profesional en odontología (deberes del dentista)}

Las profesiones contemporáneas, en tanto instituciones que responden a necesidades y demandas sociales, no sólo comparten una base cognoscitiva ("un saber") que le da su autoridad a la profesión, presentan, además, otras dos características fundamentales:

a) El acceso a un "saber hacer", esto es, una praxis, un modo de acción calificado por un agente responsable e informado por una teoría. Se trata de un saber hacer y cuándo hacer, lo que lleva a la prudencia, que es la máxima virtud de las profesiones. b) Un saber estar, es decir, la dignidad que requiere el profesar este saber, ya sea respecto a los pares (etiqueta) o respecto de aquellos que piden el servicio (ética)(8).

A principios del siglo XX, la reforma de la educación médica en EEUU resumió estos tres elementos en: servicio a la humanidad, educación de excelencia y automejoramiento/ autorregulación, designándolos respectivamente como componente moral, intelectual y organizacional de la profesión. Además, es característico de las profesiones médicas tener una competencia técnica en medicina, basada en una tradición de aprendizaje avanzado por el cual serían moralmente responsables, ubicando esta maestría al servicio de la humanidad(1,9).

Veamos cómo estos componentes se plantean en la práctica de la odontología.

\section{Componente moral}

El primer deber moral que asume el dentista es "hacer el bien" a sus pacientes, específicamente en el área de la salud bucal. Sin embargo, la decisión del odontólogo frente a un caso clínico dependerá tanto de la técnica como de la ética. Técnicamente lo que se considera "bueno" está determinado por estándares dados por la práctica y la investigación, pero no hay mucha claridad en lo que se refiere al componente ético. La mayoría de las reflexiones en ética dental tiene su raíz en antiguas teorías sobre la virtud propuestas por Sócrates y Platón, y luego por Aristóteles, que inspiraron la escuela hipocrática, pilar de la ética médica. El médico hipocrático veía al enfermo como in-firmus, un sujeto falto de firmeza, tanto física como moral. El médico debía querer el mayor bien del enfermo, pero sin contar con su voluntad, ya que carecía por principio de autonomía moral. El enfoque hipocrático era paternalista (impedía que el paciente decidiera sobre su propia enfermedad), maternal (hacía 
lo más grata posible la enfermedad al enfermo) y sacerdotal (actuaba como mediador con la divinidad y tenía poder sobre la vida y la muerte, es decir, sobre el horizonte de las ultimidades)(5).

Esta visión incluirá también a los odontólogos por largo tiempo, porque la situación de dependencia del paciente es más eleva$\mathrm{da}$, dado el alto grado de conocimiento especializado relacionado con el tratamiento comprensivo de las enfermedades dentales. La calidad de la protección estará directamente relacionada con el mantenimiento, por parte del dentista, de un elevado nivel profesional, ideales altruistas y un esmerado desempeño.

Esta relación con el paciente perdurará por siglos, pero el extraordinario avance tecnológico va a repercutir en la sociedad y en la medicina. El advenimiento de una sociedad pluralista y de los movimientos liberales exaltará las diferencias individuales respecto de valores morales fundamentales y de la interpretación del significado de la vida, la muerte, el sufrimiento, la dependencia y la atención en salud. El mayor acceso a la información ha hecho públicos numerosos casos de prácticas poco éticas. Las encuestas han demostrado que está disminuyendo la confianza de los pacientes en la integridad personal y profesional de médicos y dentistas. Como consecuencia, muchos ciudadanos de grandes potencias (en Europa y Norteamérica) están asumiendo mayores responsabilidades y tratando de mantener un control individual sobre el cuidado médico, dental y hospitalario. Estos hechos han afectado la tradicional relación odontólogo/paciente(10), redundando en que la decisión sobre "lo bueno" en una intervención clínica está determinada actualmente por algo más que la información científica y tecnológica: la elección y demanda del paciente deben equilibrarse con las obligaciones profesionales para el "no daño" y "beneficio".
Desde fines de la década del 60, la norma aceptada de práctica dental en Estados Unidos ha girado en torno a un modelo de evaluación y elección compartida entre el profesional y el paciente, en lo que se refiere al tratamiento. Nace entonces la necesidad de un "consentimiento informado", instrumento que refleja una norma mínima de esta toma de decisión compartida. Éste debería expresar plenamente la relación entre dentista y pacientes totalmente competentes.

¿Cómo manejar la situación clínica cuando el paciente no es competente? En la práctica, la mayor parte de los dentistas depende de las elecciones de los familiares y tutores, cuando están disponibles, y cuando las elecciones de estas partes no provocan daños a la salud bucal o general. Respecto de la atención de los niños, en países desarrollados se están elaborando metodologías que permitan también la participación de los niños en las decisiones médicas(11). La literatura ética dental está comenzando a desarrollar una meticulosa discusión sobre la relación del dentista con pacientes de capacidad disminuida o, directamente, sin capacidad para la toma de decisiones.

\section{Componente intelectual}

Todo profesional está obligado a adquirir y mantener la capacidad necesaria para desarrollar sus tareas profesionales y a realizar sólo aquellas tareas que están dentro de su competencia. En la práctica, cada dentista debe tomar sutiles determinaciones sobre si tiene o no competencia para realizar un diagnóstico particular, o para llevar a cabo tratamientos específi$\cos$ en determinadas circunstancias clínicas, especialmente cuando esto involucra procedimientos que no son de rutina.

En caso de necesidad, la comunidad odontológica es la que determina las normas de 
competencia, ya que para establecerlas se requieren conocimientos odontológicos. Pero la comunidad en general, con razón, puede pedir información sobre los procedimientos involucrados, especialmente en lo que se refiere al intercambio entre la calidad del servicio y el acceso a éste.

Respecto de la enseñanza ética, las responsabilidades de las facultades odontológicas son muy claras; sin embargo, existen datos que muestran que su efectividad es menor a la deseada. En un significativo número de estudiantes existe consenso acerca del cambio de objetivos que experimentan sus actitudes hacia la profesión durante el período de práctica clínica. Esto es lo que ha ocurrido durante generaciones de estudiantes de odontología, lo que sugiere que la parte clínica puede también estar necesitando una sensibilización hacia los valores humanos en el cuidado dental. En las instituciones de educación dental casi no existen docentes cuyo único o principal objetivo sea la enseñanza de la ética odontológica. La mayor parte ha desarrollado un interés personal en las cuestiones éticas o, a pesar de no tener ningún interés, ha sido arbitrariamente elegido para dar clases sobre el tema. Urgidos por los cambios en la educación médica, que incluyen el estudio de la ética médica, algunos educadores han ejercido presión para que tal expansión se implemente en la educación de la ética odontológica. Los problemas son comunes a las instituciones médicas y odontológicas de educación: las demandas de los cursos técnicos establecidos actualmente ponen trabas al reconocimiento, apoyo económico y consideración ideológica de nuevos cursos $(12,13)$.

\section{Componente organizacional. Interrelación profesional y con la comunidad. Códigos de ética y asociación profesional}

Cada profesión tiene normas, generalmente implícitas y no declaradas, sobre la correcta vinculación entre sus miembros. Desde fines de 1970, y dentro de la odontología organizada de países desarrollados, se observó un crecimiento sostenido del interés en cuestiones más elaboradas de la ética profesional. La experiencia indica que en las décadas pasadas hubo poca voluntad para enfrentar los dilemas éticos en muchas áreas sensibles de la práctica odontológica. La causa está en la subestimación del problema en cuanto a los sucesos contemporáneos abiertos a la opinión pública. Así como en otras profesiones, las obligaciones hacia el paciente son generalmente mandatarias; sin embargo, este principio no brinda respuestas automáticas a las complejidades generadas por estas situaciones. La profesión dental y los dentistas tienen la obligación de controlar la calidad del trabajo y las prácticas dentales, y reportar y referir casos de trabajos de mala calidad y prácticas no éticas. Todos entienden que los profesionales odontólogos se deben respeto mutuo, pero la mala praxis es un hecho de difícil manejo: el dentista que descubre esto podría informar al paciente acerca del trabajo mal realizado o bien ocultárselo. Por otra parte, puede contactarse con el dentista que realizó el trabajo o, posiblemente, con la sociedad dental local. Sin embargo, estos protocolos no son públicos y tampoco están establecidos en el gremio odontológico de nuestro país.

Las relaciones coprofesionales entre un dentista empleador y un dentista empleado también pueden atraer conflictos éticos cuando normas de rendimiento internas obligan a este último a brindar un servicio inferior al que considera adecuado. La bibliografía profesional está comenzando a discutir estas relaciones como cuestiones éticas y no como cuestiones prácticas o de negocios. En países desarrollados, académicos, dentistas y sus organizaciones representativas han hecho un esfuerzo conjunto para poder formular una base ética alcanzable, que sustente el suministro de un servicio de sanidad bucal de 
alta calidad. Así, y respondiendo a nuevas y significativas cuestiones generadas dentro de un clima social cambiante, la Asociación Dental Americana, luego de un considerable debate, presentó en 1992 una cantidad de revisiones y correcciones de "Principios de Ética y Código de Conducta Profesional"(14).

La evaluación objetiva y la reorganización ordenada de las doctrinas de varios códigos adaptados a la idiosincrasia de cada pueblo deberán ser alcanzadas dentro del marco de una moralidad que reconoce las fluctuaciones del comportamiento humano.

Los dentistas, en forma individual, y la profesión dental, como un todo, están también relacionados con la comunidad como educadores de la salud dental, ya sea con esfuerzos educacionales directos o monitoreando la dependencia y efectividad de los productos de salud dental comercializados. Las relaciones de los dentistas con la gran comunidad implican responsabilidades en lo que respecta a las normas correctas para la publicidad profesional. Los odontólogos tienen un importante rol en la salud pública preservando la salud dental pública y también con relación a las enfermedades epidémicas peligrosas, como el HIV; además, tienen responsabilidades referidas al acceso a la atención dental, lo que puede obligar al gremio a ser política y educacionalmente activos cuando se formulen las medidas sociales que determinen la distribución de los recursos para la asistencia en salud.

\section{Bioética y odontología}

Debido a que nuestra sociedad es pluralista y compleja, necesitamos nuevas herramientas para ayudarnos en la toma de decisiones y para tener una actitud más participativa en políticas de salud pública. La bioética es una disciplina que ha emergido para clarificar valores y elecciones, tanto de pacientes como de profesiona- les de la salud. Nació en la cultura norteamericana después de las atrocidades de la Segunda Guerra Mundial: allí se implantó como disciplina en gran número de universidades y centros de enseñanza. Es importante subrayar que esta dimensión genuinamente americana de la bioética que, principalmente a través de la teoría principialista, se ha difundido rápidamente por el entorno médico, no representa el único modo de racionalizar la respuesta moral ante los modernos dilemas éticos de la medicina. La Enciclopedia de Bioética la define como el "estudio sistemático de la conducta humana en el ámbito de las ciencias de la vida y del cuidado de la salud, examinada a la luz de los valores y de los principios". En definitiva, aquella parte de la ética o filosofía moral que estudia la licitud de las intervenciones sobre la vida del hombre, especialmente en el campo de la medicina y de las ciencias biológicas. Entre ambas definiciones configuran los cuatro rasgos definitorios de la bioética moderna: a) se trata de un marco interdisciplinario de reflexión ética; b) es básicamente una ética práctica, de aplicación inmediata en el mundo de la medicina y su entorno, cuyos principales protagonistas son el médico y el paciente; c) se trata de una reflexión ética que soporta, además, decisiones de salud pública de gran repercusión social y legal, y d) nadie puede permanecer ajeno a la bioética, porque ella determina una praxis sanitaria e involucra unos comportamientos que someten a prueba el sistema de valores que opera en una sociedad(15).

\section{Pricipialismo. Modelo de fundamentación en bioética}

Los principios son una regla intermedia entre las grandes generalizaciones filosóficas y las reglas de conducta, de modo que su interpretación y aplicabilidad dependen de factores fuera de ellos mismos. Los cuatro principios clásicos de la bioética norteamericana (autono- 
mía, beneficencia, no maleficencia y justicia) otorgan uniformidad al análisis y suponen un nuevo enfoque metodológico y procedimental para juzgar las acciones médicas, aunque son discutibles.

En el modelo denominando "principialismo jerarquizado", Diego Gracia(16) plantea ciertas modificaciones al modelo originario de los principios, dotándoles de mayor racionalidad ética y solidez doctrinal. Gracia considera que los principios de no-maleficencia y justicia son, de algún modo, independientes del principio de autonomía y jerárquicamente superiores, porque obligan moralmente siempre, incluso contra la voluntad de las personas, en este caso de los enfermos. Es en este primer escalón donde se postula la mayor exigencia del "bien común" sobre el "bien particular" de la autonomía. En el segundo escalón, el principio de la beneficencia no es enteramente separable del de autonomía. La nomaleficencia expresa, por otra parte, el criterio universal de hacer bien a todos no haciéndoles el mal, mientras que la beneficencia proporciona un concepto de bien que parece referirse, en la concepción del autor, a un bien particular. Por eso ese bien particular está densamente adherido a la autonomía. El primer escalón, o nivel 1, constituido por nomaleficencia y justicia, viene a representar una "ética de mínimos": lo básico exigible para dar carácter ético al acto médico o sanitario y siempre un verdadero deber. Beneficencia y autonomía comprenden el nivel 2, y cuando siguen al nivel 1 convierten el acto médico en una "ética de máximos", transformando la acción de cumplir el mero deber en satisfacción del paciente (en felicidad). El primer nivel es exigible por el derecho, el segundo sería específico de la moral. El nivel 1 sitúa el acto médico ante un deber universal -de universalización-, el nivel 2 en un rango de exigencia ética mayor pero de particularización.
Estos principios proporcionan al quehacer odontológico un conjunto de valores que establecen parámetros para la mayor parte de los aspectos de las evaluaciones del profesional. En primer lugar, la vida del paciente, la salud general y la salud bucal del paciente, entendida como un funcionamiento bucal apropiado y sin dolores, constituirían la ética de mínimos. La autonomía del paciente; lo que le ocurra al cuerpo del paciente (incluyendo la importancia que éste le otorga a la salud, el confort, el costo y otros valores); las preferencias de los dentistas por ciertas prácticas (incluyendo diferentes filosofías de prácticas dentales); consideraciones estéticas, desde el punto de vista de experimentadas prácticas dentales; consideraciones de eficiencia, que puedan incluir, por parte del dentista, consideraciones sobre el costo, se insertarían dentro de la ética de máximos.

"Compromiso de servicio" o "compromiso con el público" son expresiones frecuentes para resaltar una de las características de las profesiones. Pero éstas admiten varias interpretaciones, con implicancias distintas en la práctica real; por ejemplo, los tipos de sacrificios que los dentistas están profesionalmente comprometidos a realizar por sus pacientes o los tipos de riesgos de vida y salud, bienestar financiero o reputación que un dentista está obligado a enfrentar. Las preguntas vinculadas a la correcta relación entre empresa y compromiso con el paciente, y el sacrificio de los propios intereses involucrados han sido discutidas en todos los períodos de la profesión dental. El consenso es que (especialmente en situaciones de emergencia) el paciente oral y la salud en general demandan, por parte de los dentistas, sacrificios importantes que afectan a sus conveniencias personales y sus intereses económicos. Desde la aparición de HIV y el SIDA las implicancias son aún más urgentes en relación con la obligación de priorizar al paciente. 


\section{Conclusión}

Este artículo entregó una visión global del debate ético que se manifiesta en el ejercicio profesional de la odontología, tanto en Chile como en países desarrollados. La ética profesional es lo que mantiene unida a la profesión odontológica. Debemos entonces reevaluar la de nuestro "gremio" y desarrollar un pensamiento apropiado para la sociedad actual. La prevención y el cuidado de la salud bucal valen tanto para aquellos que tienen medios como para aquellos que no los tienen, y son responsabilidades importantes de la odontología comunitaria.

Los dentistas en general, y los cirujanos maxilofaciales en particular, se han sensibilizado respecto del consentimiento informado, principalmente debido al incremento en el número de pacientes que han iniciado acciones legales y a la existencia de jueces que han dictado sentencia basándose en la ausencia de tal consentimiento. Sin embargo, su verdadero valor no ha sido aún analizado ni enfatizado por los dirigentes del conjunto de profesionales de nuestro país. Mientras el público tiene una preocupación creciente por los derechos de los pacientes, el incremento en los costos de seguro por mala praxis genera la misma preocupación entre médicos y dentistas.

La evaluación por pares se está transformando en un componente esencial de aquellos sistemas de atención dental sinceramente interesados en su responsabilidad hacia el público y en brindar servicios de alta calidad. Deberíamos trabajar en la elaboración de protocolos que faciliten este tipo de evaluaciones, enseñándolos en las facultades y cuya aplicación clínica sea real y efectiva.

Quienes utilizan los servicios de los hospitales, tanto médicos como dentales, se quejan de que los costos del cuidado de la salud crecen el doble con relación al costo de vida. En odontología es más evidente y, entonces, aparece el dilema de lo que es justo para la atención odontológica actual. En nuestra sociedad de libre mercado, y con el creciente interés de reducir los costos de salud a través de la competencia, se ha fomentado que los profesionales de la salud hagan publicidad, pero no se ha implementado una real legislación al respecto. La publicidad del profesional dental ha quedado como el eterno ejemplo de la práctica no ética, y dadas las características sociales actuales valdría la pena reevaluar estas prácticas y analizar sus verdaderas consecuencias.

La creciente aparición de nuevas facultades de odontología entregará pronto al país un conjunto de profesionales técnicamente preparados para brindar servicios a la comunidad. Sin embargo, como el énfasis en la educación dental ha estado orientado generalmente sólo hacia la incorporación de habilidades técnicas, probablemente no haya existido una mayor apreciación de las diferencias que separan a la odontología como profesión de la serie de ocupaciones cuyo principal objetivo es la generación de ganancias. El crecimiento de la conciencia en los temas éticos, desde fines de los 70 hasta los 80 , y el cambio sufrido por la práctica dental han promovido en países desarrollados la necesidad de revisar el currículo en la enseñanza de la ética dental y demás tópicos relacionados. Países latinoamericanos, como México, Colombia y Argentina, también han tomado conciencia de la necesidad inminente de incluir la bioética dentro de los programas de estudio de la carrera odontológica. Sin ir más lejos, en Chile, en noviembre de 2004, se realizó el Primer Simposio Latinoamericano de Bioética y Odontoestomatología, auspiciado por la Universidad de Chile. La odontología como profesión siempre ha tomado seriamente la cuestión de 
la ética dental. Pero como esfera de estudio (una subdisciplina dentro del estudio de la teoría moral y la ética profesional) la ética dental es todavía muy joven.

Por lo tanto, el rol de los profesionales de la salud es triple: brindar la mejor atención a los pacientes en forma individual, preocuparse por la comunidad en la que se desempeñan y utilizar los recursos con los que cuentan de la forma más efectiva.

\section{Agradecimientos}

Estudio realizado dentro del Programa Internacional de Formación en Ética de la Investigación Biomédica y Psicosocial, gracias al grant 1R25TW06056 del Fogarty International Center (National Institute of Health), otorgado al Centro Interdisciplinario de Estudios en Bioética de la Universidad de Chile.

\section{Referencias}

1. Nash DA. Ethics in dentistry: review and critique of Principles of Ethics and Code of Professional Conduct. J Am Dent Assoc 1984; 109(4): 597-603.

2. Ibarra Barrón C. Elementos fundamentales de ética. México: Alhambra Mexicana; 1996: 137.

3. Kant I. Crítica de la razón pura. Madrid: Alfaguara; 1878.

4. Gracia D. La tradición médica y el criterio del bien del enfermo: El paternalismo médico. En: Gracia D. Fundamentos de Bioética. Madrid: Eudema; 1991: 23-45.

5. Lolas F. Bioética y Antropología Médica. Santiago de Chile: Mediterráneo; 2000: 41-70.

6. Jurado CE. Cronología de la historia de la odontología. Tribuna Odontológica 2004; 1(6) [Sitio en Internet] Disponible en http://www.medilegis.com/

7. Kenny NP. Bioethics and Canadian dentistry. J Can Dent Assoc 1997;63(9): 690-694.

8. Lolas F. Bioética: el diálogo moral en las ciencias de la vida. Santiago de Chile: Universitaria; 1998.

9. Nash DA. The oral physician. Creating a new oral health professional for a new century. J Dent Educ 1995; 59(5):587-597.

10. Agranatti P. Bioética en odontología. Odontomarketing 2001; 2(9) [Sitio en Internet] Disponible en http://www.odontomarketing.com/numeros\%20anteriores/ART_18_ENE_2001.htm

11. Harrison Ch, Kenny NP, Sidarous M, Rowell M. Bioethics for clinicians: Involving children in medical decisions. Can Med Assoc J 1997;156: 825-828.

12. Nash DA. A pragmatic primer lessons from natural science for the profession of dentistry. $J$ Public Health Dent 1996; 56(5): 291-300.

13. Nash DA. The profession of dentistry: The University of Kentucky's curriculum in professional ethics. J Am Coll Dent 1996; 63(1): 25-29.

14. American Dental Association 2004. Principles of Ethics and Code of Professional Conduct, with Official Advisory Opinions. 
15. Escríbar A. Raíces de la bioética en la tradición ético-filosófica occidental y actuales desafíos. Anales de la Universidad de Chile 1998; Sexta Serie(8).

16. Gracia D. La tradición política y el criterio de justicia: El bien de terceros. En: Gracia D. Fundamentos de Bioética. Madrid: Eudema; 1991: 200-204.

Recibido: 03 de enero de 2006

Aceptado: 31 de enero de 2006

74 